\title{
Antidiabetic potential of Balanites Aegyptiaca kernel, flesh and their combination against streptozotocin-induced hyperglycemia in male rats
}

\author{
Saed A Al-Thobaiti*, Isam M Abu Zeid \\ Department of Biological Sciences, Faculty of Sciences, King Abdulaziz University, PO Box 139109, Jeddah 21323, Saudi \\ Arabia \\ *For correspondence: Email: saiad1402@gmail.com; Tel: +966-503052017
}

Sent for review: 6 August 2018

Revised accepted: 26 January 2019

\begin{abstract}
Purpose: To investigate the antidiabetic effect of Balanites aegyptiaca fruit kernel, flesh and their mixture on streptozocin (STZ)-induced diabetes in male rats.

Methods: Six-week-old male Wistar rats were divided into nine groups: (1) control; (2) kernel; (3) flesh; (4) kernel + flesh; (5) STZ; (6) STZ + kernel; (7) STZ + flesh; (8) STZ + (kernel + flesh) and (9) STZ + metformin. Body weight changes, fasting blood glucose and serum insulin were assessed. Haematoxylin and Eosin (H\& E) stained pancreas sections were examined microscopically for the number and status of $\beta$ cells.

Results: Administration of Balanites aegyptiaca kernel, flesh and their mixture significantly increased rat body weight compared to STZ-treated rats. In addition, the hypoglycemic effect of kernel, flesh and their mixture was noticed. In STZ-treated rats, administration of Balanites aegyptiaca kernel and kernel + flesh mixture significantly increased serum insulin $(p<0.05)$. Histopathological examination revealed a marked increase in the islets cell population with cellular activation, with superior effect in STZ + kernel group and STZ + (kernel + flesh) group.

Conclusion: Balanites aegyptiaca showed a hypoglycemic effect which is comparable to metformin action. Further studies are required to determine its suitability as an anti-diabetic agent in humans
\end{abstract}

Keywords: Balanites aegyptiaca, Diabetes, Histopathology, Insulin, Pancreas

\begin{abstract}
This is an Open Access article that uses a funding model which does not charge readers or their institutions for access and distributed under the terms of the Creative Commons Attribution License (http://creativecommons.org/licenses/by/4.0) and the Budapest Open Access Initiative (http://www.budapestopenaccessinitiative.org/read), which permit unrestricted use, distribution, and reproduction in any medium, provided the original work is properly credited.
\end{abstract}

Tropical Journal of Pharmaceutical Research is indexed by Science Citation Index (SciSearch), Scopus, International Pharmaceutical Abstract, Chemical Abstracts, Embase, Index Copernicus, EBSCO, African Index Medicus, JournalSeek, Journal Citation Reports/Science Edition, Directory of Open Access Journals (DOAJ), African Journal Online, Bioline International, Open-J-Gate and Pharmacy Abstracts

\section{INTRODUCTION}

Diabetes mellitus (DM) is a metabolic syndrome which is characterized by a chronic hyperglycemic status generated due to deficiency in insulin, resistance to insulin effect or both [1,2]. Recently, the International Diabetes Federation (IDF) 7th edition of the Diabetes Atlas specified that 415 million people worldwide are diabetics [3]. Globally, a high incidence of DM is expected to exist in the Middle East and North Africa [4].

Medicinal herbs and alternative medicine are safer and more effective alternatives compared to oral DM therapy [5]. Balanites aegyptiaca is a widespread terrestrial tree. It is native to most of Africa, the Middle East, Southern Asia and 
Pakistan [6]. The biologically active constituents of Balanites aegyptiaca include saponins, tannins, flavonoids, cardiac glycosides, fatty acids and sterols [7] The purified fractions of Balanites aegyptiaca possess significant antioxidant, antiinflammatory, antimicrobial and cytotoxic potentials [8]. In Egyptian folk medicine, the Balanites aegyptiaca is utilized as an oral antidiabetic remedy [9]. Balanites aegyptiaca fruits showed significant hypoglycemic effects in streptozocine (STZ)-induced hyperglycemia in animals [10,11]. Moreover, another study revealed a hypoglycemic nephroprotective effect of Balanites aegyptiaca fruit (flesh) in streptozocine-induced DM in rats [12]. Similarly, Baragob et al [13] revealed a hypoglycemic action of Balanites aegyptiaca kernel in alloxaninduced diabetic rats.

Currently, there are no research studies that investigated the antidiabetic, biochemical and the histological effects of the whole Balanites aegyptiaca fruit (flesh and kernel) in type 2 DM animal model.

This study was carried out to investigate the antidiabetic, biochemical and histological effects of the whole Balanites aegyptiaca fruit (kernel, flesh and their combination) in STZ-induced type $2 \mathrm{DM}$ in rats. In addition, it compared the antidiabetic, biochemical and histological effects of the whole Balanites aegyptiaca fruit (flesh and kernel) with that of either fruit flesh alone or fruit kernel alone.

\section{EXPERIMENTAL}

\section{Plant material}

Fruits of Balanites aegyptiaca were obtained from a local market in Jeddah, Saudi Arabia. The plant was identified and authenticated by a taxonomist, $\mathrm{Dr}$ Abdalla Elfeel, Faculty of Meteorology, Environment and Arid Land Agriculture, King Abdulaziz University, Jeddah, Saudi Arabia.

\section{Drugs and chemicals}

STZ was purchased from Sigma, USA. Metformin (Glucophage, $500 \mathrm{mg}$ tablet, Merck Santé, France) was purchased from Jeddah, Saudi Arabia. All other chemicals were of high analytical grade.

\section{Experimental animals}

Male Wister rats $(180-240 \mathrm{~g})$ were obtained from The Mansour Scientific Foundation for Research and Development, Jeddah, Saudi
Arabia. Rats were housed at $25^{\circ} \mathrm{C}$ with 12-hour light/dark cycle and offered water and food. They acclimatized to the laboratory conditions for one week prior to the initiation of the experiment. Animals were handled according to the Ethical Guidelines of King Abdulaziz University, Saudi Arabia, and strict compliance with the guidelines of the International standard and Institutional Animal Care and Use committee (IACUC) [14]. The work protocol was approved by the Scientific Research Ethics Committee of King Fahd Medical Research Center, King Abdulaziz University, Jeddah, Saudi Arabia (approval no. 118-01-009-0173).

\section{Preparation of methanol extracts of Balanites aegyptiaca fruit}

The method of Al-Malki et al [11] was adopted with some modifications. Also the crude powder of Balanites aegyptiaca (either kernel, flesh or their mixture) was placed in a stoppered container with methanol and allowed to stand at room temperature for a period of at least 3 days until the soluble matter dissolved. The rotary evaporator was employed for the efficient and gentle removal of solvents from samples. Then the mixture was strained, the Marc (the damp solid material) was pressed, and the combined liquids were clarified by filtration or decantation after standing and boiled to evaporate the methanol and then freeze dry for complete evaporation.

\section{Preparation of STZ solution}

Immediately before use, STZ (45 mg/kg) [15] was

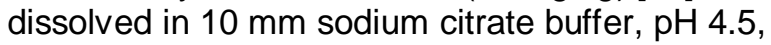
then a suitable volume of $0.25 \mathrm{M}$ sodium chloride solution was added to adjust the isotonicity.

\section{Determination of working dose of Balanites aegyptiaca fruit extracts}

A preliminary study was conducted with different doses of Balanites aegyptiaca fruit (Kernel, Flesh or their mixture) and the most effective dose (650 $\mathrm{mg} / \mathrm{kg}$ ) was chosen.

\section{Animal studies}

Rats were divided into 9 groups $(n=10)$. Group I (control): rats in this group were intraperitoneal (i.p.) injected with citrate buffer $(0.05 \mathrm{M}, \mathrm{pH}$ 4.5). They were also intragastric (i.g.) administered distilled water. Group II (Kernel): rats in this group were i.g. administered 650 $\mathrm{mg} / \mathrm{kg}$ methanol extract of Balanites aegyptiaca kernel. Group III (Flesh): rats in this group were i.g. administered $650 \mathrm{mg} / \mathrm{kg}$ methanol extract of 
Balanites aegyptiaca flesh. Group IV (Mix): rats in this group were i.g. administered $650 \mathrm{mg} / \mathrm{kg}$ methanol extract of Balanites aegyptiaca kernel + flesh mixture. Group V (STZ): rats in this group were i.p. injected STZ (45 mg/kg) [16].Group $\mathrm{VI}(S T Z$ + Kernel): STZ-treated rats were i.g. administered $650 \mathrm{mg} / \mathrm{kg}$ methanol extract of Balanites aegyptiaca kernel. Group VII (STZ + flesh):

STZ-treated rats were i.g. administered 650 $\mathrm{mg} / \mathrm{kg}$ methanolic extract of Balanites aegyptiaca flesh. Group VIII(STZ + Mix): STZ-treated rats were i.g. administered $650 \mathrm{mg} / \mathrm{kg}$ methanolic extract of Balanites aegyptiaca kernel + flesh mixture. Group IX (STZ + metformin): STZtreated rats were i.g. administered $200 \mathrm{mg} / \mathrm{kg}$ metformin [17]. Treatment of control and diabetic rats with methanol extract of Balanites aegyptiaca fruit kernel, flesh and their mixture were continued for 6 weeks.

\section{Assessment of body weight}

The body weight (BW) of each rat was determined separately at the beginning of the experiment, 3 weeks and 6 weeks thereafter. The percent (\%) body weight gain (BWG) was calculated after 3 and 6 weeks of treatment using Eq 1.

$\% B W G=\{($ final BW - initial BW $) /$ initial BW $\} 100$

\section{Assessment of fasting blood glucose}

Fasting blood glucose was estimated after one week of STZ injection, 3 weeks after and then at the end of the 6th week by taking blood samples from the tail vein using Free Style Freedom Lite, Abbott [18].

\section{Sample collection}

At the end of the experimental period, the rats were euthanized using deep ether anaesthesia, pancreases were dissected out, washed with normal saline and preserved in $10 \%$ buffered formalin solution until they were used for the histopathological study. Blood samples were collected from the orbital plexus of their veins, left to clot, and centrifuged at $3000 \mathrm{rpm}$ for serum separations.

\section{Assessment of fasting serum insulin}

Enzyme-linked immunosorbent assay (ELISA) (Dynex) fully automated immunoassay was used to determine fasting serum insulin concentration in all experimental groups using rats ELISA kit of Thermo Scientific, USA. A monoclonal antibody specific for rat insulin was utilized. The primary antibody was biotin antibody and the assay Avidin D, Horseradish Peroxidase (Av-HRP) was used to bind the detection antibody, biotin with high affinity. Cytokine concentrations were calculated using a standard lyophilized recombinant rat insulin.

\section{Assessment of histopathological changes}

Formalin-fixed pancreases from all the groups were dehydrated in ascending grades of isopropyl alcohol and cleared in xylene. The slides were stained with Haematoxylin and Eosin $(H \& E)$ and examined microscopically for the number and status of $\beta$ islets of Langerhans.

\section{Statistical analysis}

Data were expressed as mean \pm standard error of the mean (SEM). Statistical analysis of data was performed using one-way analysis of variance (ANOVA) followed by Tukey's post-hoc test. The Significant level was set at $p \leq 0.05$. The statistical analysis was performed using SPSS software for Windows, version 22, Armonk, NY. Figures are constructed using GraphPad Prism software, version 5.

\section{RESULTS}

\section{Effect of Balanites aegyptiaca extracts on rat body weight}

The results of this study demonstrated that, after 3 and 6 weeks, rats injected with STZ showed significant decrease in BW when compared to the control group $(p \leq 0.001)$ (Figure 1).

After 3 weeks, rats in both STZ + kernel and STZ + metformin groups showed significant increase in BW in comparison to the STZ group $(p \leq 0.01)$. On the other hand, after 3 weeks, rats in both STZ + flesh and STZ + Mixture groups showed non-significant changes in $\mathrm{BW}$ in comparison to STZ group (Figure 1).

After 6 weeks, rats in the STZ + kernel, STZ + mixture, and STZ + metformin groups showed a significant increase in $\mathrm{BW}$ when compared to the STZ group $(p \leq 0.001,0.05$, and 0.001 respectively). On the other hand, after 6 weeks, rats in the STZ + flesh group showed nonsignificant change in BW when compared to STZ group (Figure 1). 


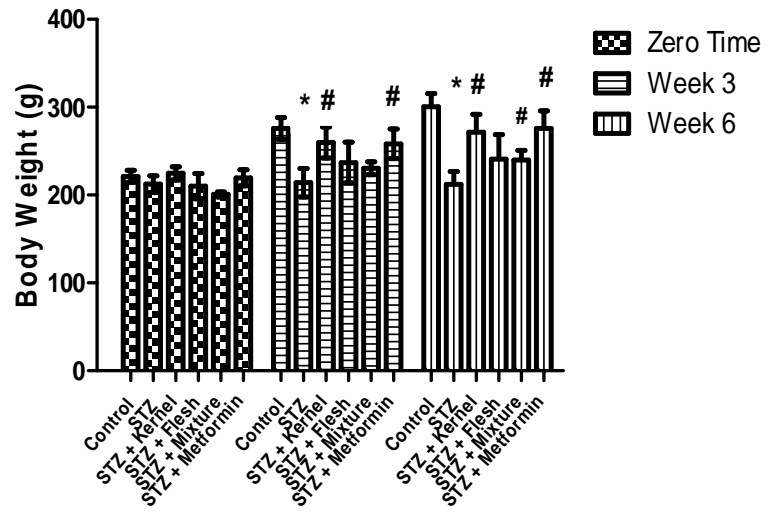

Figure 1: Effect of methanol extract of Balanites aegypiaca kernel, flesh and their mixture on STZinduced changes in body weight measured on the 1st week, 3rd week and 6th week. Data was expressed as mean \pm SEM $(n=10) ;{ }^{*}$ indicates significant difference compared to the control group at $p \leq 0.05$. indicates significant difference compared to the STZ group at $p$ $\leq 0.05$

In addition, the data presented in Figure 2 illustrate that after 3 and 6 weeks, rats injected with STZ showed a significant decrease in BW gain in comparison to the control group ( $p \leq$ 0.001).

After 3 weeks and 6 weeks, rats in the STZ + Kernel, STZ + Flesh, STZ + MiXture, and STZ + Metformin groups showed a significant increase in \% BW when compared to the STZ group (Figure 2).

Table 1 shows that gavaged methanol extract of Balanites aegypiaca kernel, flesh and their mixture in normal rats resulted in non-significant change in body weight and \% body weight gain at all-time points in comparison to the control group.

\section{Effect of Balanites aegyptiaca kernel, flesh or mixture on fasting blood glucose}

After 1, 3 and 6 weeks, rats injected with STZ showed significant increase in fasting blood glucose (FBG) when compared to the control group $(p \leq 0.001)$ (Figure 3 ).

After 1, 3 and 6 weeks, rats in the STZ + Kernel, STZ + Flesh, STZ + Mixture, and STZ + Metformin groups showed a significant decrease in FBG as compared to the STZ group (Figure 3)

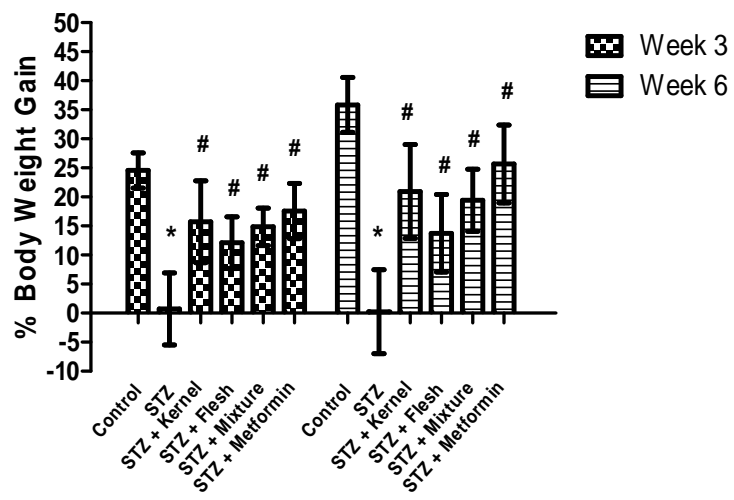

Figure 2: Effect of methanolic extract of Balanites aegypiaca kernel, flesh and their mixture on STZinduced changes in \% body weight gain calculated after 3 weeks and 6 weeks. Data are expressed as mean \pm SEM $(n=10)$. indicates significant difference compared to the control group at $\mathrm{p} \leq 0.05$. " indicates significant difference compared to the STZ group at $p$ $\leq 0.05$

Table 1: Effect of different parts of Balanites aegypiaca fruit (kernel, flesh and a mixture of kernel and flesh) on body weight, \% body weight gain, fasting blood glucose, and fasting serum insulin measured in normal rats at different time points.

\begin{tabular}{|c|c|c|c|c|c|c|c|c|c|}
\hline & \multicolumn{3}{|c|}{ Body weight (g) } & \multicolumn{2}{|c|}{$\begin{array}{l}\text { Body weight } \\
\text { gain (\%) }\end{array}$} & \multicolumn{3}{|c|}{ Blood glucose (mg/dl) } & \multirow{2}{*}{$\begin{array}{c}\begin{array}{c}\text { Serum } \\
\text { insulin } \\
(\mu \mathrm{lU} / \mathrm{ml})\end{array} \\
6 \text { weeks }\end{array}$} \\
\hline & $\begin{array}{c}1 \\
\text { Week }\end{array}$ & $\begin{array}{c}3 \\
\text { Weeks }\end{array}$ & $\begin{array}{c}6 \\
\text { Weeks }\end{array}$ & $\begin{array}{c}3 \\
\text { Week }\end{array}$ & $\begin{array}{c}6 \\
\text { Weeks }\end{array}$ & $\begin{array}{c}1 \\
\text { Weeks }\end{array}$ & $\begin{array}{c}3 \\
\text { Weeks }\end{array}$ & $\begin{array}{c}6 \\
\text { Weeks }\end{array}$ & \\
\hline Control & $\begin{array}{l}221 \pm \\
6.8\end{array}$ & $\begin{array}{l}276 \pm \\
12.3\end{array}$ & $\begin{array}{l}301 \pm \\
14.9\end{array}$ & $\begin{array}{l}24.6 \pm \\
3.0\end{array}$ & $\begin{array}{l}35.8 \pm \\
4.7\end{array}$ & $\begin{array}{l}97.6 \pm \\
6.8\end{array}$ & $\begin{array}{l}101.7 \pm \\
5.7\end{array}$ & $\begin{array}{l}85.8 \pm \\
2.3\end{array}$ & $17.5 \pm 0.9$ \\
\hline Kernel & $\begin{array}{l}212 \pm \\
5.7\end{array}$ & $\begin{array}{l}254 \pm \\
14.2\end{array}$ & $\begin{array}{l}282 \pm \\
12.8\end{array}$ & $\begin{array}{l}19.5 \pm \\
5.4\end{array}$ & $\begin{array}{l}32.8 \pm \\
6.4\end{array}$ & $\begin{array}{l}103 \pm \\
7.9\end{array}$ & $\begin{array}{l}93.1 \pm \\
5.6\end{array}$ & $\begin{array}{l}90.4 \pm \\
3.5\end{array}$ & $21.5 \pm 0.7^{\mathrm{a}}$ \\
\hline Flesh & $\begin{array}{l}211 \pm \\
6.4\end{array}$ & $\begin{array}{l}270 \pm \\
12.6\end{array}$ & $\begin{array}{l}288 \pm \\
17.8\end{array}$ & $\begin{array}{l}27.9 \pm \\
5.2\end{array}$ & $\begin{array}{l}36.5 \pm \\
8.3\end{array}$ & $\begin{array}{l}102.4 \pm \\
3.8\end{array}$ & $\begin{array}{l}100.3 \pm \\
6.0\end{array}$ & $\begin{array}{l}92.5 \pm \\
5.8\end{array}$ & $20.4 \pm 0.8^{a}$ \\
\hline Mixture & $\begin{array}{l}215 \pm \\
7.8\end{array}$ & $\begin{array}{l}257 \pm \\
11.8\end{array}$ & $\begin{array}{l}296 \pm \\
14.1\end{array}$ & $\begin{array}{l}19.5 \pm \\
3.5\end{array}$ & $\begin{array}{l}37.5 \pm \\
5.0\end{array}$ & $\begin{array}{l}101.3 \pm \\
6.5\end{array}$ & $\begin{array}{l}97.2 \pm \\
5.6\end{array}$ & $\begin{array}{l}91.9 \pm \\
3.0\end{array}$ & $18.9 \pm 1.4$ \\
\hline
\end{tabular}

Results are expressed as mean \pm SEM $(n=10) .{ }^{a}$ indicates significant difference compared to the control group at $p \leq 0.05$ 
Table 1 shows that i.g. administration of the methanolic extract of Balanites aegypiaca kernel, flesh and their mixture in normal rats resulted in a non-significant change in FBG at all-time points in comparison to the control group.

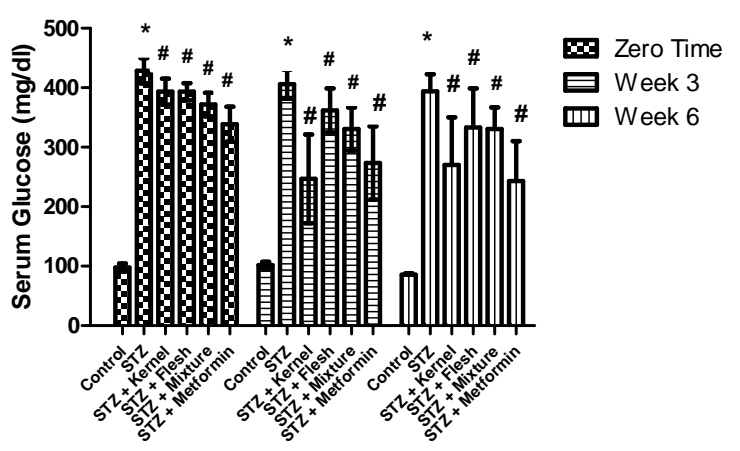

Figure 3: Effect of methanolic extract of Balanites aegypiaca kernel, flesh and their mixture on STZinduced changes in fasting blood glucose levels measured at 1 st week, 3rd week and 6th week. Data are expressed as mean \pm SEM $(n=10)$. "indicates significant difference compared to the control group at $\mathrm{p} \leq 0.05$. \# indicates significant difference compared to the STZ group at $p \leq 0.05$

\section{Effect of Balanites aegyptiaca kernel, flesh or mixture on fasting serum insulin}

After 6 weeks, rats injected with STZ showed a significant decrease in fasting serum insulin (FSI) relative to the control group ( $p \leq 0.001)$ (Figure 4).

After 6 weeks, rats in the STZ + Kernel, STZ + Mixture, and STZ + Metformin groups showed a significant increase in FSI in comparison to the STZ group $(p \leq 0.01,0.001$, and 0.001 respectively) (Figure 4 ).

Table 1 showed that i.g. administration of the methanolic extract of Balanites aegypiaca kernel and flesh in normal rats resulted in significant increase in $\mathrm{FSI}$ measured at 6 weeks when compared to the control group ( $p \leq 0.01$ and 0.05). Conversely, Table 1 showed that i.g. administration of the methanolic extract of Balanites aegypiaca mixture in normal rats resulted in a non-significant change in $\mathrm{FSI}$ measured at 6 weeks when compared to the control group.

\section{Effect of Balanites aegyptiaca kernel, flesh or mixture on pancreatic tissue histopathology}

In control rat pancreas, islets of Langerhans were frequently seen as a lightly stained areas among the deeply stained exocrine acini (Figure $5 \mathrm{~A}$ ). At higher power, the islets were varying in size and shape depending on the lane of cutting. The islets consisted of clusters of cells with illdefined outlines and normal population. The cells showed large rounded vesicular active nuclei. The types of islets cell could be identified by their location, staining and size of nuclei. Beta cells were central in position and rounded shape and with active rounded vesicular nuclei. They were separated by thin wall capillaries (Figure 5 B).

In the diabetic rat pancreas, islets were less frequently seen in reared sections. They were also potentially small (Figure $5 \mathrm{C}$ ). Beta cells showed smaller dark stained degenerated nuclei. Most cells are clumped together while other showed unstained cytoplasm or the presence of vacuoles (Figure 5, D and E).

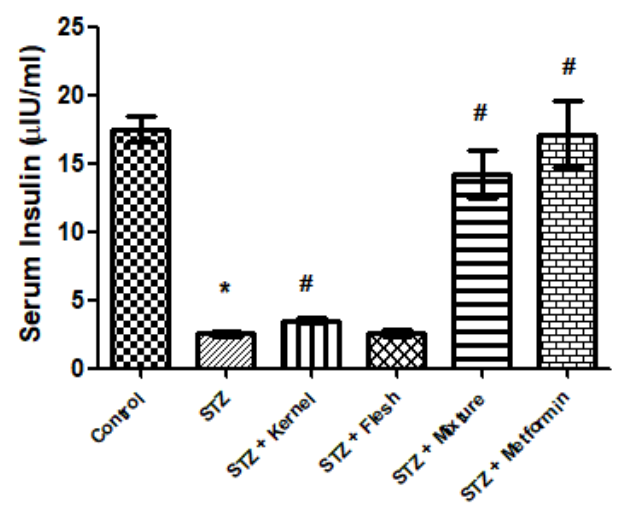

Figure 4: Effect of methanolic extract of Balanites aegyptiaca kernel, flesh and their Mixture on the STZinduced rat decrease in serum insulin concentration measured after 6 weeks. Results are expressed as mean \pm SEM $(n=10)$. indicates significant difference compared to the control group at $p \leq 0.05$. " indicates significant difference compared to the STZ group at $p$ $\leq 0.05$

In diabetic + kernel rat pancreas, islets were nearly of normal frequency, cell populations and size (Figure 6 A). Beta cells showed large central vesicular active nuclei. No signs of cell clumping or vacuolation (Figure $6 \mathrm{~B}$ ). In diabetic + flesh rat pancreas, islets were almost of normal size (Figure $6 \mathrm{C}$ ). Beta cells showed a normal population with well stained acidophilic cytoplasm and central vesicular active nuclei (Figure 6 D). In diabetic + kernel + flesh mixture rat pancreas, islets showed a normal cell population (Figure $6 \mathrm{E}$ ), they showed also scattered cells possessing darkly stained nuclei and clumped together (Figure 6 F). In diabetic + metformin rat pancreas, islets of Langerhans showed a normal population (Figure 6G) with centrally located large cells with pale cytoplasm and active large nuclei but there were still 
some cells with dark stain in active nuclei similar to those seen in non-treated diabetics (Figure $6 \mathrm{H}$ ).
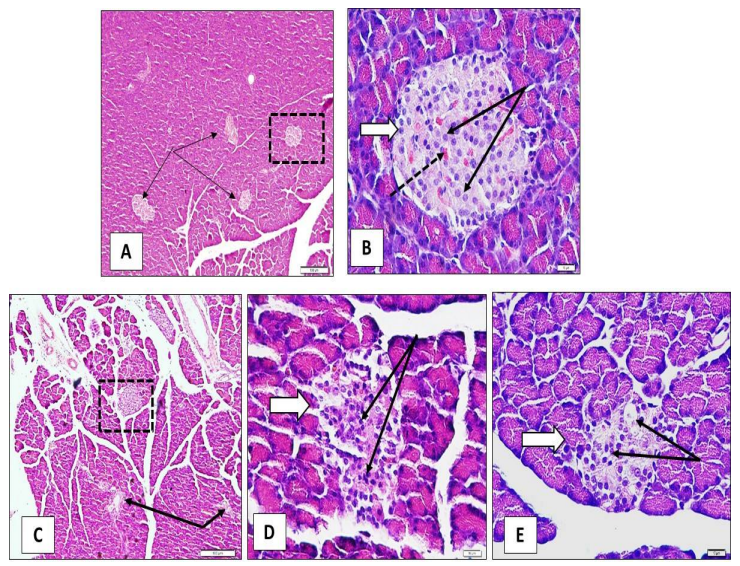

Figure 5: $A$ and $C(H \& E \times 100)$ and $B, D$, and $E(H$ \& $E \times 600$ ) of rat pancreatic tissue. Photo $A$ of control rat, showed the frequency of islets of Langerhans (arrows and dotted square) of normal size (white arrows). Photo B of control rat showed the normal size and population of cells with well stained acidophilic cytoplasm and central vesicular active nuclei (white black arrows). Photo B of control rat also showed the blood capillaries between the cells with thin walled and non-dilated (dotted arrow). Rat pancreatic tissue of STZ-treated group showing islets of Langerhans (arrows \& dotted square, photo C) of smaller size (white arrows, photo $D$ and E). Note the decrease population of cells, some showed unstained vacuolated cytoplasm, and most are aggregated together and have small dark stained degenerated nuclei (black arrows photos $\mathrm{D}$ and $\mathrm{E}$ )

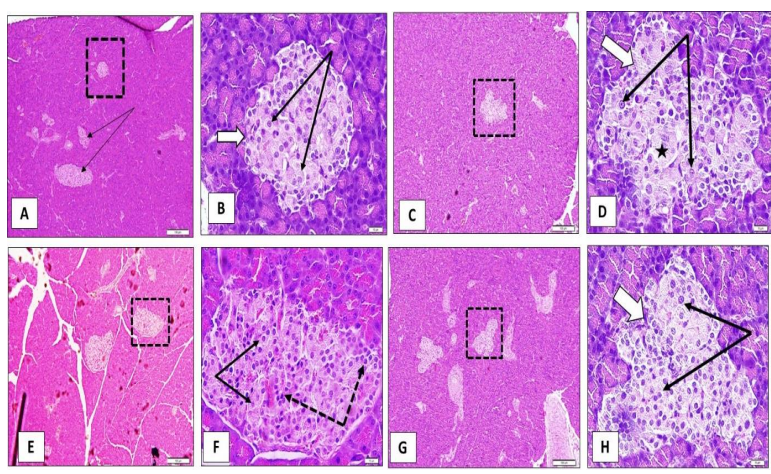

Figure 6: Photos $A, C, E$, and $G(H \& E \times 100)$ and photo $B, D, F$, and $H(H \& E \times 600)$ of rat pancreatic tissue. Photo A of STZ + Kernel group showed islets of Langerhans (arrows \& dotted square). Photo B of STZ + Kernel group showed a normal population of cells with well stained acidophilic cytoplasm and central vesicular active nuclei (black arrows). Photo C of STZ + Flesh group showed islets of Langerhans (dotted square). Photo D of STZ + Flesh group showed normal population with well stained acidophilic cytoplasm and central vesicular active nuclei (black arrows), still some cells showed slightly unstained cytoplasm and ill-defined nuclei (star). Photo $\mathrm{E}$ of rat pancreatic tissue of STZ + kernel and flesh mixture showed islets of Langerhans (dotted square). Photo $\mathrm{F}$ of STZ + kernel and the flesh mixture group showed that most cells showed normal active nuclei (black arrows). A Few cells are clumped together and showed small pyknotic nuclei (dotted arrows). Photo G of rat pancreatic tissue of STZ + metformin showed islets of Langerhans (dotted square). Photo $\mathrm{H}$ of rat pancreatic tissue of STZ + metformin showed central located large cells with pale cytoplasm and active large nuclei (black arrows). Still some cells showed dark stained in active nuclei similar to those seen in non-treated diabetics

$H$ \& $E$ stained sections from rat pancreas of control rats treated with the Kernel, Flesh and their Mixture showed a marked increase in islets cells population with cellular activation (large vesicular nuclei) compared with the control group with the superior effect in Kernel group and Mixture group (Figure 7).
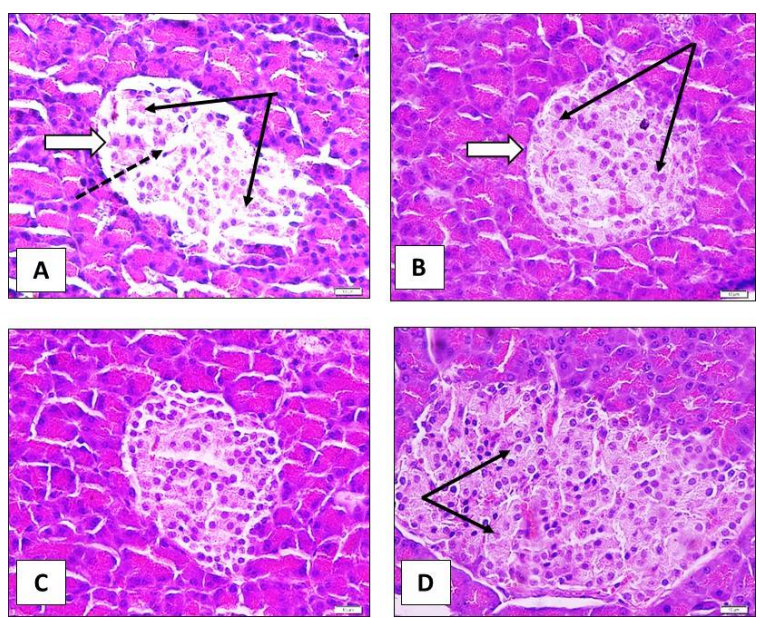

Figure 7: Sections from rat pancreas showing A: control; B: Kernel; C: Flesh; D: Mixture. The photos B, $\mathrm{C}$, and $\mathrm{D}$ showed aremrkable increase in islets cells population with cellular activation (large vesicular nuclei) in the treated groups compared to the control group (photos 1) with a superior effect on Kernel group (photo B) and Mixture group (photo D) (H\&E stain $x$ 600)

\section{DISCUSSION}

Diabetes mellitus is a chronic disease that is associated with a group of metabolic disorders. The main symptom of DM is elevated blood sugar level commonly known as hyperglycemia. The underlying causes of DM constitute either deficiency in insulin secretion or resistance to insulin action or both [19].

Studies have already reported that DM cannot be treated with traditional medicine alone, as it has not been able to adjust the level of glucose completely and has many side effects [20]. In this respect, research on medicinal plants has shown their importance in diabetes therapy, as 
toxicological studies have proven them to be the safest [20].

This study aims at investigating the potential hypoglycemic effect of the methanolic extract of different parts of Balanites aegypiaca fruit, including kernel, flesh and their mixture in a model of STZ-induced DM in male rats.

Diabetes is characterized by weight loss. The results of this study showed that STZ injection in rats resulted in a marked reduction in body weight in rats. Administration of the methanolic extract of Balanites aegypiaca kernel, flesh and their mixture to the rats brought about an increased body weight gain relative to STZtreated rats. Similarly, supplementation of Balanites aegyptiaca kernel cake (10 and $20 \%$ ) for three weeks significantly increased the body weight determined in alloxan-induced DM in rats [21].

The results of the present study showed a hypoglycemic effect of methanolic extract of Balanites aegypiaca kernel, flesh and their mixture as indicated by the reduction in the levels of fasting blood glucose when compared with STZ-treated rats. Comparison between kernels, flesh and their mixture showed no significant difference between the hypoglycemic effects of the three fractions as estimated by ANOVA test. The effect of the three fractions is comparable to that of the reference oral hypoglycemic agent, metformin.

Similar to this results, the aqueous extract of the mesocarp of fruits of Balanites aegypiaca was reported to have an antidiabetic effect in STZinduced DM in mice [22]. In addition, our results are in line with other data obtained by Qusti et al [12] which reported that administration of Balanites aegyptiaca fruit (cortex) extract in a dose of $600 \mathrm{mg} / \mathrm{kg} /$ day significantly decreased the blood glucose concentration. Al-Malki et al [11] reported that Balanites aegyptiaca fruit reduced the levels of fasting blood glucose in a model of streptozocine-induced DM in rats.

A previous study by Ghanem et al [23] presented data that support the blood glucose lowering effect of the herbal tea of Balanites aegyptiaca fruits in STZ-induced diabetes in the rats. Recently, Ezzat et al [24] recorded antidiabetic effect of the methanolic extract of the powdered pericarps of Balanites aegyptiaca fruit against STZ-induced diabetic rats. Similarly, supplementation of Balanites aegyptiaca kernel cake (10 and $20 \%$ ) for a period of three weeks significantly reduced blood glucose in alloxaninduced DM in rats [21]. In agreement with this study results Shafik et al. [25] noticed that Balanites aegyptiaca kernel extract lowered the blood glucose levels in alloxan-induced DM in rats.

As far as we know, this study is the first study that reported the hypoglycemic action of kernel and flesh mixture of Balanites aegyptiaca fruits in STZ-induced DM in rats.

To identify the hypoglycemic mechanism of the methanolic extract of Balanites aegypiaca, serum insulin concentrations were measured in all the treated groups and compared with the STZtreated group. The results of this study showed that Balanites aegypiaca kernel and mixture resulted in a significant increase in serum insulin compared to STZ group. In contrast, Balanites aegypiaca flesh resulted in a non-significant increase in serum insulin compared to STZ group. The most probable mechanism of the effect may be the preservation of $\beta$-cells in the pancreas as found in the histopathological study conducted in this work.

The result of this study showed that Balanites aegyptiaca had a regenerative effect on pancreatic $\beta$-cells. As the density of $\beta$-cells population and their size in the treated groups were increased by the kernel and mixture administration compared to the diabetic group. The current research aims to restore the efficiency of pancreatic $\beta$-cells and improve their ability to secrete insulin as a basic line in the treatment of diabetes [26].

There are no research studies that reported the ability of various parts of Balanites aegyptiaca fruit increasing the secretion of insulin and protecting the pancreas against the defect in STZ-induced diabetes in rats. However, concerning Balanites aegyptiaca active constituents, Ghanem et al [23] reported that the hypoglycemic effect of Balanites aegyptiaca might be related to the presence of bioactive components such as flavonoids, saponin, carvacrol and/or cinnamyl alcohol. Both carvacrol and cinnamyl alcohol enhance pancreatic secretion of insulin from $\beta$-cells and glucose homeostasis.

In this study, the use of the plant extracts in the non-diabetic animals did not affect rat weights and blood glucose levels compared to the control rats. However, it was observed that the groups that took the kernel and flesh extracts showed increased serum insulin level compared to the control group and this was accompanied by increased $\beta$-cells population in the pancreas. 


\section{CONCLUSION}

The results of this study showed that the methanol extract of the kernel and flesh of Balanites aegyptiaca and their mixture has a hypoglycemic activity in rats. The kernel extract, as well as the mixed extract, enhance insulin secretion after diabetes induction. The extracts of all Balanites aegyptiaca fruit parts also reverse weight loss caused by diabetes mellitus. Thus, Balanites aegyptiaca is a potential adjunct to dietary and drug therapies for better DM control.

\section{DECLARATIONS}

\section{Conflict of Interest}

No conflict of interest associated with this work.

\section{Contribution of Authors}

We declare that this work was done by the authors named in this article and all liabilities pertaining to claims relating to the content of this article will be borne by the authors. Saed A AlThobaiti: Review of literature, study design, conduct experimental model, collect samples, biochemical and histopathological analysis, statistical analysis and manuscript writing, reviewing and publishing. Isam M Abu Zeid: Research idea and reviewing the text writing.

\section{REFERENCES}

1. Mirhoseini $M$, Baradaran A, Rafieian-Kopaei, $M$. Medicinal plants, diabetes mellitus and urgent needs. $J$ Herbmed Pharmacol 2013; 2: 53-54.

2. Heindel JJ, Blumberg $B$, Cave $M$, Machtinger $R$, Mantovani A, Mendez MA, Nadal A, Palanza P, Panzica $G$, Sargis R, Vandenberg LN, Vom Saal F. Metabolism disrupting chemicals and metabolic disorders. Reprod Toxicol 2017; 68: 3-33.

3. Meo SA, Usmani AM, Qalbani E. Prevalence of type 2 diabetes in the Arab world: impact of GDP and energy consumption. Eur Rev Med Pharmacol Sci 2017; 21: 1303-1312.

4. Alotaibi A, Perry L, Gholizadeh L, Al-Ganmi A. Incidence and prevalence rates of diabetes mellitus in Saudi Arabia: An overview. J Epidemiol Glob Health 2017; 7: 211-218.

5. Pandey A, Tripathi $P$, Pandey $R$, Srivatava $R$, Goswami S. Alternative therapies useful in the management of diabetes: A systematic review. J Pharm Bioallied Sci 2011; 3: 504-512.

6. Elfeel $A A$. Effect of seed pre-treatment and sowing orientation on germination of Balanites aegyptiaca (L.) Del. seeds. Amer-Eurasian J Agri \& Environ Sciences 2012; 12: 897-900.
7. Chothani DL, Vaghasiya HU. A review on Balanites aegyptiaca Del (desert date): phytochemical constituents, traditional uses, and pharmacological activity. Pharmacogn Rev 2011; 5: 55-62.

8. Montasser AOS, Saleh H, Ahmed-Farid OA, Saad A, Marie MS. Protective effects of Balanites aegyptiaca extract, Melatonin and Ursodeoxycholic acid against hepatotoxicity induced by Methotrexate in male rats. Asian Pac J Trop Med 2017; 10: 557-565.

9. Gnoula C, Megalizzi V, De Neve N, Sauvage $S$, Ribaucour F, Guissou P, Duez P, Dubois J, Ingrassia L, Lefranc F, Kiss R, Mijatovic T. Balanitin-6 and - 7: diosgenyl saponins isolated from Balanites aegyptiaca Del. display significant anti-tumor activity in vitro and in vivo. Int J Oncol 2008; 32: 5-15.

10. Gad MZ, El-Sawalhi MM, Ismail MF, El-Tanbouly ND. Biochemical study of the anti-diabetic action of the Egyptian plants fenugreek and balanites. Mol Cell Biochem 2006; 281: 173-183.

11. Al-Malki AL, Barbour EK, Abulnaja KO, Moselhy SS. Management of hyperglycaemia by ethyl acetate extract of Balanites aegyptiaca (Desert Date). Molecules (Basel, Switzerland) 2015; 20: 14425-14434.

12. Qusti SY, Sharahili RY, Moselhy SS. Role of Balanites aegyptiaca in attenuation of diabetic nephropathy. Int $J$ Life Sci Biotechnol Pharma Res 2015; 3: 8-14.

13. Baragob AE, Almalki WH, Shahid I, Bakhdhar FA, Bafhaid HS, Eldeen OM. The hypoglycemic effect of the aqueous extract of the fruits of Balanites aegypticea in Alloxan-induced diabetic rats. Pharmacognosy Res 2014; 6: 1-5.

14. Bennett RA, Pegg AE. Alkylation of DNA in rat tissues following administration of Streptozotocin. Can Res 1981; 41: 2786-2790.

15. National, Research Council, Guide for the Care and Use of Laboratory Animals, 7th ed. National Academy Press, Washington DC, 1996.

16. Zafar M, Naeem-ul-Hassan Naqvi S, Ahmed M, Kaim Khani ZA. Altered liver morphology and enzymes in streptozotocin-induced diabetic rats. Int J Morphol 2009; 27: 719-725.

17. Li X, Xu Z, Jiang Z, Sun L, Ji J, Miao J, Zhang X, Li X, Huang $S$, Wang $T$, Zhang $L$. Hypoglycemic effect of catalpol on high-fat diet/streptozotocin-induced diabetic mice by increasing skeletal muscle mitochondrial biogenesis. Acta Biochim Biophys Sin (Shanghai) 2014; 46: 738-748.

18. Petlevski R, Hadzija M, Bajalo JL, Juretic D. Effects of acarbose on alanine aminotransferase and aspartate aminotransferase activities in the liver of control and diabetic CBA mice. Acta Pharm 2006; 56:87-93.

19. Ribeiro $C$, de Alencar Mota CS, Voltarelli FA, de Araújo $M B$, Botezelli JD, de Oliveira CAM, de Mello MAR. Effects of moderate intensity physical training in neonatal alloxan- administered rats. J Diabetes Metab 2010; 1: 1-5.

20. Putta S, Yarla NS, Kilari EK, Surekha C, Aliev G, Divakara MB, Santosh MS, Ramu R, Zameer F, Mn NP,

Trop J Pharm Res, February 2019; 18(2): 270 
Chintala R, Rao PV, Shiralgi $Y$, Dhananjaya $B L$. Therapeutic potentials of triterpenes in diabetes and its associated complications. Curr Top Med Chem 2016; 16: 2532-2542.

21. Nadro MS, Samson FP. The effects of Balanite aegyptiaca kernel cake as supplement on alloxan induced diabetes mellitus in rats. J Appl Pharm Sci 2014; 4: 58-61.

22. George DH, Ali HK, El Abbas OA. Evaluation of the biological activity of Balanites aegyptiaca Del Saponin in the control of type 11 diabetes mellitus on rats and the growth of Escherichia coli. Ahfad J Women Change 2006; 23: 2-3.

23. Ghanem KZ, Ghanem HZ, Ramadan MM, Mabrok HB. The effect of herbal tea from Balanites aegyptiaca fruits on streptozotocin-induced diabetes mellitus in rats. Int. $J$ Pharmtech Res. 2016; 9: 8-15.

24. Ezzat S M, Abdel Motaal A, El Awdan SAW. In vitro and in vivo antidiabetic potential of extracts and a furostanol saponin from Balanites aegyptiaca. Pharm Biol 2017; 55: 1931-1936.

25. Shafik NH, Shafek RE, Michael HN, Eskander EF. Phytochemical study and antihyperglycemic effects of Balanites aegyptiaca kernel extract on alloxan induced diabetic male rat. J Chem Pharm Res 2016; 8: 128-136.

26. Nurdiana S, Goh YM, Ahmad H, Dom SM, Azmi1 NS, Noor Mohamad Zin NS and Mahdi Ebrahimi $M$. Changes in pancreatic histology, insulin secretion and oxidative status in diabetic rats following treatment with Ficus deltoidea and vitexin. BMC Complement Altern Med 2017; 17: 1-17. 